\title{
Comparative Study of gp130 Cytokine Effects on Corticotroph AtT-20 Cells - Redundancy or Specificity of Neuroimmunoendocrine Modulators?
}

\author{
Christoph J. Auernhammer ${ }^{a}$ Florian B. Kopp ${ }^{a}$ George Vlotides ${ }^{a}$ \\ Franziska Dorn $^{a}$ Nicola B. Isele ${ }^{a}$ Gerald Spöttla Neziha Cengic $^{a}$ \\ Matthias M. Weber ${ }^{b}$ Giorgio Senaldi ${ }^{c}$ Dieter Engelhardt ${ }^{a}$ \\ a Medizinische Klinik II, Klinikum Grosshadern, Ludwig-Maximilians-Universität, München, and b Klinik II und

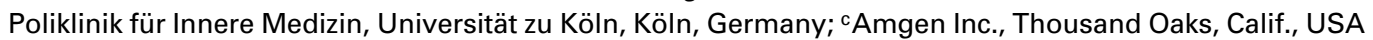

\section{Key Words}

ACTH • Corticotroph AtT-20 • gp130 cytokines • POMC · SOCS $\cdot$ STAT

\begin{abstract}
Objective: This comparative in vitro study examined the effects of all known gp130 cytokines on murine corticotroph AtT-20 cell function. Methods: Cytokines were tested at equimolar concentrations from 0.078 to $10 \mathrm{nM}$. Tyrosine phosphorylation of the signal transducer and activator of transcription (STAT) 3 and STAT1, the STATdependent suppressor of cytokine signaling (SOCS)-3 promoter activity, SOCS-3 gene expression, STAT-dependent POMC promoter activity and adrenocorticotropic hormone (ACTH) secretion were determined. Results: Leukemia inhibitory factor (LIF), human oncostatin $M$ (OSM) and cardiotrophin (CT)-1 (LIFR/gp130 ligands), as well as ciliary neurotrophic factor (CNTF) and novel neurotrophin-1/B-cell stimulating factor-3 (CNTFR $\alpha /$ LIFR/ gp130 ligands) are potent stimuli of corticotroph cells in vitro. In comparison, interleukin (IL)-6 (IL-6R/gp130 ligand) and IL-11 (IL-11R/gp130 ligand) exhibited only modest direct effects on corticotrophs, while murine
\end{abstract}

OSM (OSMR/gp130 ligand) showed no effect. Conclusion: (i) CNTFR complex ligands are potent stimuli of corticotroph function, comparable to LIFR complex ligands; (ii) IL-6 and IL-11 are relatively weak direct stimuli of corticotroph function; (iii) differential effects of human and murine OSM suggest that LIFR/gp130 (OSMR type I) but not OSMR/gp130 (OSMR type II) are involved in corticotroph signaling. (iv) CT-1 has the hitherto unknown ability to stimulate corticotroph function, and ( $v$ ) despite redundant immuno-neuroendocrine effects of different gp130 cytokines, corticotroph cells are preferably activated through the LIFR and CNTFR complexes.

Copyright $\odot 2004$ S. Karger AG, Basel

\section{Introduction}

The gp130 cytokine family currently encompasses seven members, namely leukemia inhibitory factor LIF (LIF), oncostatin M (OSM), cardiotrophin (CT)-1, ciliary neurotrophic factor (CNTF), novel neurotrophin-1/B-cell stimulating factor-3 (NNT-1/BSF-3), interleukin (IL)-6 and IL-11 [1-3]. The common receptor subunit gp130 associates with specific receptor subunits, resulting in the

\section{KARGER \\ Fax +41613061234 \\ E-Mail karger@karger.ch \\ www.karger.com \\ (C) 2004 S. Karger AG, Basel \\ 1021-7401/04/0114-0224\$21.00/0 \\ Accessible online at: \\ www. karger.com/nim}

Christoph Auernhammer, MD, Medizinische Klinik II

Ludwig-Maximilians-Universität München, Standort Grosshadern

Marchioninistrasse 15, DE-81377 München (Germany)

Tel. +49 897095 0, Fax +49 897004418

E-Mail Christoph.Auernhammer@med2.med.uni-muenchen.de 
heterodimeric receptor complexes LIFR/gp130 and OSMR/gp130, the tripartite receptor complex CNTFR $\alpha /$ LIFR/gp130 and the homodimeric receptor complexes IL-6R/gp130 and IL-11R/gp130 [1-3]. Several gp130 cytokines have been shown to be important modulators of hypothalamo-pituitary-adrenal (HPA) and stimulates corticotroph axis function in various states of stress or inflammation [2-5]. Especially the action of LIF has been well characterized at pituitary corticotroph level, using the in vitro model of murine corticotroph AtT-20 cells. LIF binds to the LIFR/gp130 complex and stimulates corticotroph Janus kinase (Jak) and signal transducer and activator of transcription (STAT) signaling and subsequent STAT-dependent POMC gene expression and adrenocorticotropic hormone (ACTH) secretion [2, 5]. Also, the role of STAT-dependent suppressor of cytokine signaling (SOCS)-3 gene expression and its role as an endogenous negative regulator of cytokine-induced corticotroph function has been examined by experiments using LIF as a corticotroph stimulus [6]. Stimulatory effects on corticotroph cell function in vitro have also been described for human OSM (hOSM) [7-11], CNTF and NNT-1/BSF-3 [12], IL-6 [13-16] and IL-11 [17], respectively. However, as these effects have been investigated under various conditions, these studies cannot show the relative potency of each gp130 cytokine in corticotroph function. To the best of our knowledge, no studies have been published regarding the effects of CT-1 and murine OSM (mOSM) on corticotroph cells.

In the current study, we compared the effects of equimolar concentrations of all known gp130 cytokines on murine corticotroph AtT-20 cell function in vitro. Despite obvious redundancy of gp130 cytokines as immunoneuroendocrine modulators of HPA axis activity, this study demonstrates a specific role of gp130 cytokines in the corticotroph-stimulating function. Our data show that the ligands of the LIFR and CNTFR complexes are the major direct stimuli of corticotroph function, as indicated by STAT tyrosine phosphorylation, STAT-dependent SOCS-3 promoter activity and gene expression and POMC promoter activity and ACTH secretion.

\section{Materials and Methods}

\section{Materials}

Recombinant human (rh)NNT-1/BSF-3 was expressed in Escherichia coli $[18]$ and stocked in a solution containing $5 \mathrm{~m} M$ sodium citrate, $\mathrm{pH} 4$. All other cytokines tested were diluted in the same sodium citrate buffer, and the buffer solution was used as a control. Recombinant murine (rm)LIF was purchased from Chemicon Inter- national (Temecula, Calif., USA). All other cytokines, i.e. rhOSM, rmCT-1, rhCNTF, rmIL-6, rmIL-11 and rmOSM were purchased from R\&D Systems (Minneapolis, Minn., USA).

\section{Cell Culture}

AtT-20/D16v-F2 cells were cultured in DMEM supplemented with $10 \%$ fetal calf serum as described recently [12]. Cells were appropriately plated and grown for $48 \mathrm{~h}$. Afterwards, cells were preincubated with serum-depleted medium (containing $0.2 \%$ BSA) for $24 \mathrm{~h}$ and subsequently incubated with equimolar concentrations of each cytokine tested.

\section{Northern Blot Analysis}

Northern blot analysis was performed as described recently [12]. Briefly, RNA was extracted using TRIZOL ${ }^{\circledR}$ (Invitrogen, Karlsruhe, Germany) and $20 \mu \mathrm{g}$ total RNA per lane were electrophoresed and transferred to a nylon membrane. Using random-primed DNA labeling, a SOCS-3 probe template (nt 15-762, GeneBank Accession U88328) and a $\beta$-actin DECAprobe ${ }^{\circledR}$ (Ambion, Austin, Tex., USA) were labeled with $\left(\alpha-{ }^{32} \mathrm{P}\right) \mathrm{CTP}$. Following hybridization with QuickHyb Rapid $^{\circledR}$ (Stratagene, La Jolla, Calif., USA) autoradiographs were exposed to Kodak Biomax MS ${ }^{\circledR}$ film (Eastman Kodak, Rochester, N.Y., USA).

\section{Luciferase Assay}

Transient transfection of AtT-20 cells with a -706/+64 rat POMC promoter-luciferase construct in PGEM7Z vector (kindly provided by Dr. Malcolm Low, Vollum Institute, Portland, Oreg., USA) or a $-2757 /+929$ mSOCS-3 promoter-luciferase construct in pGL3Basic vector [19] was performed with Superfect ${ }^{\circledR}$ (Quiagen, Hilden, Germany), as described recently [12]. In the current experiments, luciferase activities were measured in untreated controls and cells treated with equimolar concentrations $(10 \mathrm{n} M)$ of various gp130 cytokines. The relative increase in untreated vs. stimulated luciferase activity was determined for each experiment.

\section{Protein Extraction and Western Blotting}

Protein extraction, SDS gel electrophoresis and Western blotting was performed as described recently [12]. Tyrosine phosphorylation was detected with specific primary antibodies against phosphorylated STAT3 (pSTAT3) and pSTAT1 (Upstate Biotechnology, Lake Placid, N.Y., USA) and a peroxidase conjugated secondary antibody (Pierce, Rockford, Ill., USA). Peroxidase was detected by the chemiluminescent substrate SuperSignal West Dura Extended Duration Substrate (Pierce) and membranes exposed to XOMAT-AR ${ }^{\circledR}$ film (Eastman Kodak). For the determination of protein loading, blots were stripped and re-incubated with antibodies to STAT3 and STAT1 (Santa Cruz Biotechnology, Santa Cruz, Calif., USA), respectively.

\section{ACTH Assay}

ACTH was measured with a commercial radioimmunoassay (Diagnostic System Laboratories, Webster, Tex., USA) in the supernatants of AtT-20 cells stimulated with various gp130 cytokines for $24 \mathrm{~h}$.

\section{Statistical Analysis}

Densitometric analysis of specific bands in Northern blots was performed with NIH Image 1.59 software, and JMP 5.0.1 software was used for statistical analysis. The data are expressed as means \pm 
Fig. 1. Effects of gp130 cytokines on corticotroph STAT3 phosphorylation. Corticotroph AtT-20 cells were incubated with equimolar concentrations $(10 \mathrm{n} M)$ of various gp130 cytokines for 5 and $15 \mathrm{~min}$, respectively. Tyrosine phosphorylation of STAT3 (pSTAT3) and protein loading of the respective STAT3 protein were determined by the use of specific antibodies. A Using densitometric analysis, the ratio of pSTAT3 vs. STAT3 for each treatment group was determined and the respective ratio of the control group was set at 1.0. The relative ratio of tyrosine STAT3 phosphorylation was calculated in comparison to this negative control group. Means \pm SE of 3 independently performed experiments are shown (significant differences are indicated: $* \mathrm{p}<0.05$; $* * \mathrm{p}<$ $0.01 ; * * * \mathrm{p}<0.001$, vs. control, ). B One representative Western blot out of 3 performed.

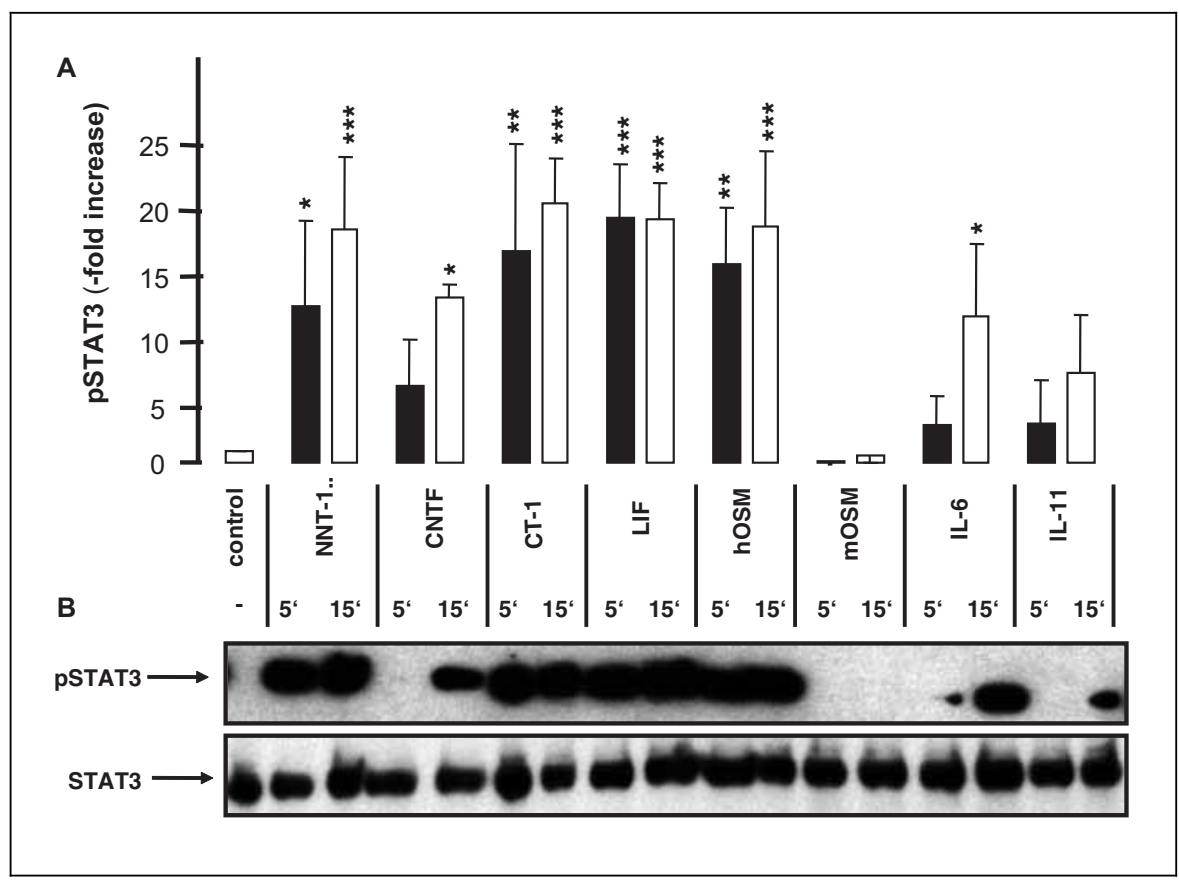

SE of at least three independent experiments. The mean of a single treatment group versus the mean of a single control group were compared using Student's t test and $p<0.05$ was considered statistically significant.

\section{Results}

Tyrosine Phosphorylation of STAT3 and STAT1 by Various gp130 Cytokines

Tyrosine phosphorylation of STAT3 at 5 min was induced 17- to 20-fold by LIF, hOSM and CT-1, 13-fold by NNT-1/BSF-3 but 6 -fold by CNTF, and approximately 3-fold by IL-6 and IL-11, respectively (fig. 1). At $15 \mathrm{~min}$, tyrosine phosphorylation of STAT3 was induced 20- to 21-fold by LIF, hOSM and CT-1, 14- to 19-fold by CNTF and NNT-1/BSF-3 and 7- to 12-fold by IL-11 and IL-6, respectively (fig. 1).

Tyrosine phosphorylation of STAT1 at 5 min was induced 5- to 11-fold by hOSM, CT-1 and LIF, 17-fold by NNT-1/BSF-3 but only 2-fold by CNTF, and was hardly induced by IL-6 and IL-11 (fig. 2). At $15 \mathrm{~min}$, tyrosine phosphorylation of STAT1 was induced 14- to 22-fold by hOSM, LIF and CT-1, 14-fold by NNT-1/BSF-CNTF-3 but only 5-fold by CNTF and 2- to 5-fold by IL-11 and IL-6, respectively (fig. 2).
No effect on STAT3 or STAT1 phosphorylation was found for mOSM (fig. 1, 2), although high bioactivity and STAT activation of this cytokine preparation could be demonstrated in adrenocortical Y-1 cells (data not shown).

In a dose-response study, tyrosine phosphorylation of STAT3 by various gp 130 cytokines ranging from 0.078 to $10 \mathrm{n} M$ was examined ( 2 independently performed experiments, fig. 3A, B). STAT3 phosphorylation was detected with concentrations as low as 0.078 to $0.312 \mathrm{n} M$ for hOSM, LIF, CT-1, and NNT-1/BSF-3. In contrast, higher concentrations of $0.625-2.5 \mathrm{n} M$ were required to induce STAT3 phosphorylation by CNTF, IL-11 and IL-6. Cytokine-induced STAT3 phosphorylation seemed to reach a plateau when using concentrations of 5.0-10.0 $\mathrm{n} M$ of each respective cytokine. mOSM did not induce STAT3 phosphorylation in AtT-20 cells at any concentration tested.

\section{SOCS-3 Promoter Activity and Gene Expression by}

Various gp130 Cytokines

Promoter activity of a murine $-2757 /+929$ SOCS-3 promoter-luciferase construct (fig. 4A) and SOCS-3 mRNA expression (fig. 4B) were examined following incubation of AtT-20 cells with different gp130 cytokines in an equimolar concentration of $10 \mathrm{n} M$. SOCS-3 promoter activity was significantly stimulated 3 - to 5 -fold above 
Fig. 2. Effects of gp130 cytokines on corticotroph STAT1 phosphorylation. Corticotroph AtT-20 cells were incubated with equimolar concentrations $(10 \mathrm{n} M)$ of various gp130 cytokines for 5 and $15 \mathrm{~min}$, respectively. Tyrosine phosphorylation of STAT1 (pSTAT1) and protein loading of the respective STAT1 protein was determined by the use of specific antibodies. A Using densitometric analysis, the ratio of pSTAT1 vs. STAT1 for each treatment group was determined and the respective ratio of the control group was set at 1.0. The relative ratio of tyrosine STAT1 phosphorylation was calculated in comparison to this negative control group. Means \pm SE of 3 independently performed experiments (significant differences are indicated: $* \mathrm{p}<0.05{ }^{* *} \mathrm{p}<0.01 ; * * * \mathrm{p}<$ 0.001 , vs. control). B One representative Western blot out of 3 performed.

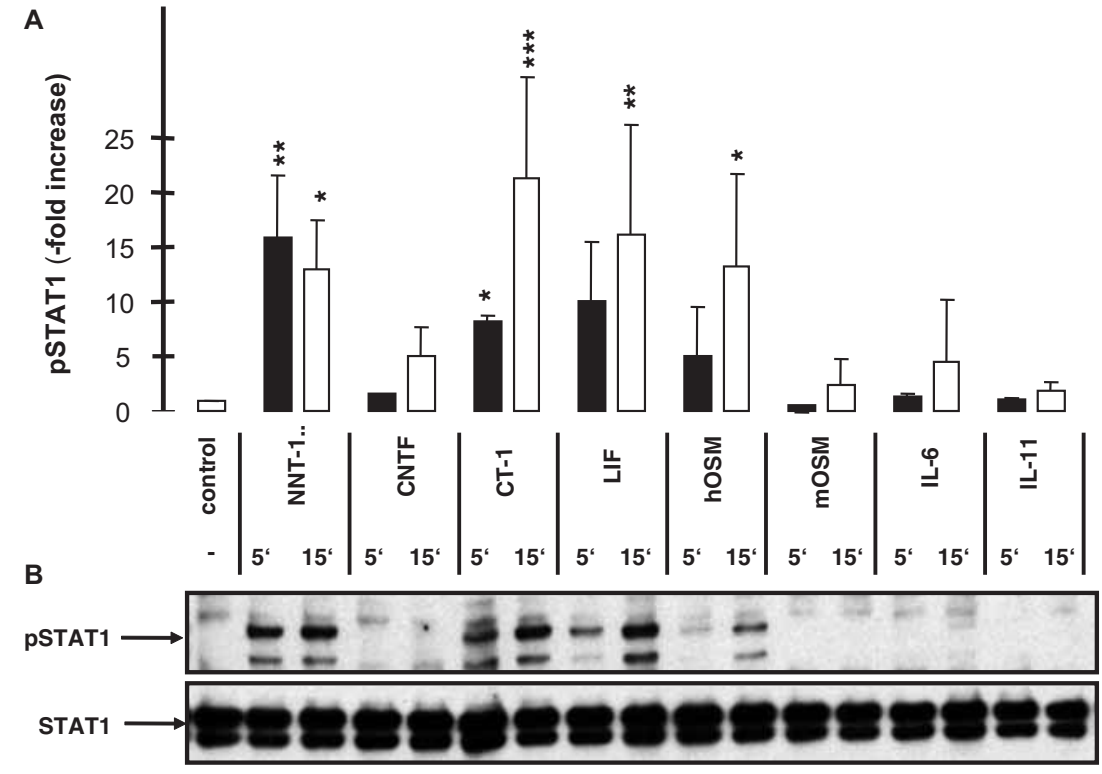

A

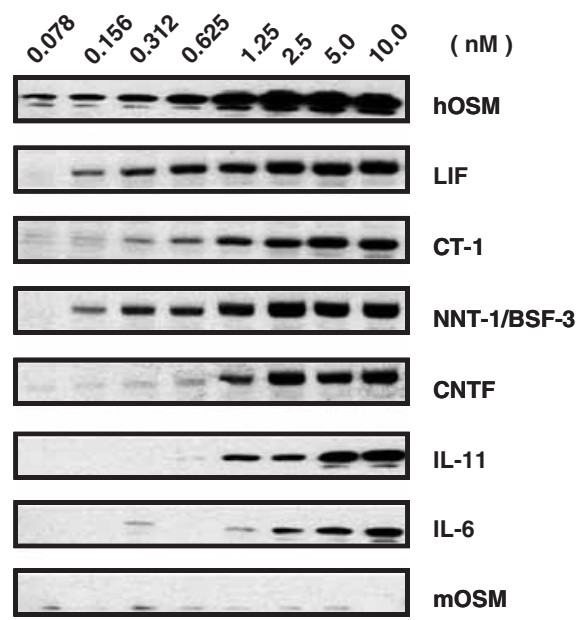

B

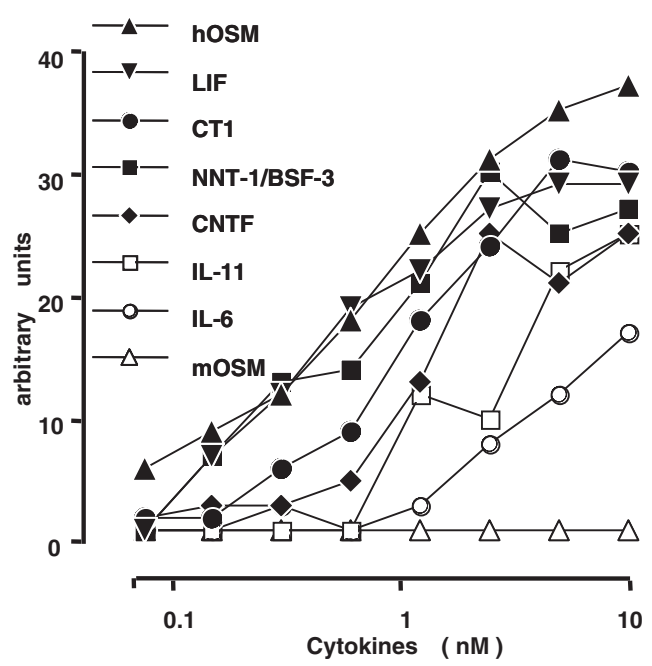

Fig. 3. Dose-response curve of gp130 cytokines on corticotroph STAT3 phosphorylation. A In a dose-response study, corticotroph AtT-20 cells were incubated with different gp130 cytokines in concentrations ranging from 0.078 to $10.0 \mathrm{n} M$. Tyrosine pSTAT3 was demonstrated by a specific antibody. Equal protein loading was verified with an antibody against total STAT3 (data not shown). One representative Western blot out of 2 performed is shown. B Normalized densitometry data of $\mathbf{A}$. 
Fig. 4. Effects of gp 130 cytokines on corticotroph SOCS-3 promoter activity and gene expression. A Corticotroph AtT-20 cells were incubated with equimolar concentrations $(10 \mathrm{n} M)$ of various gp 130 cytokines for $6 \mathrm{~h}$. Reporter gene activity of a transiently transfected -2757/+929 murine SOCS-3 promoter-luciferase (luc) construct was assayed. Reporter gene activity induced by the various gp130 cytokines was calculated as $\mathrm{x}$ fold increase in comparison to an unstimulated control. Significant differences are indicated: ${ }^{* *} \mathrm{p}<0.01 ; * * * \mathrm{p}<0.001$, vs. control. B AtT-20 cells were incubated with equimolar concentrations $(10 \mathrm{n} M)$ of various gp130 cytokines for $45 \mathrm{~min}$. SOCS-3 mRNA expression was determined by Northern blot analysis. Shown is one representative Northern blot out of 3 performed.

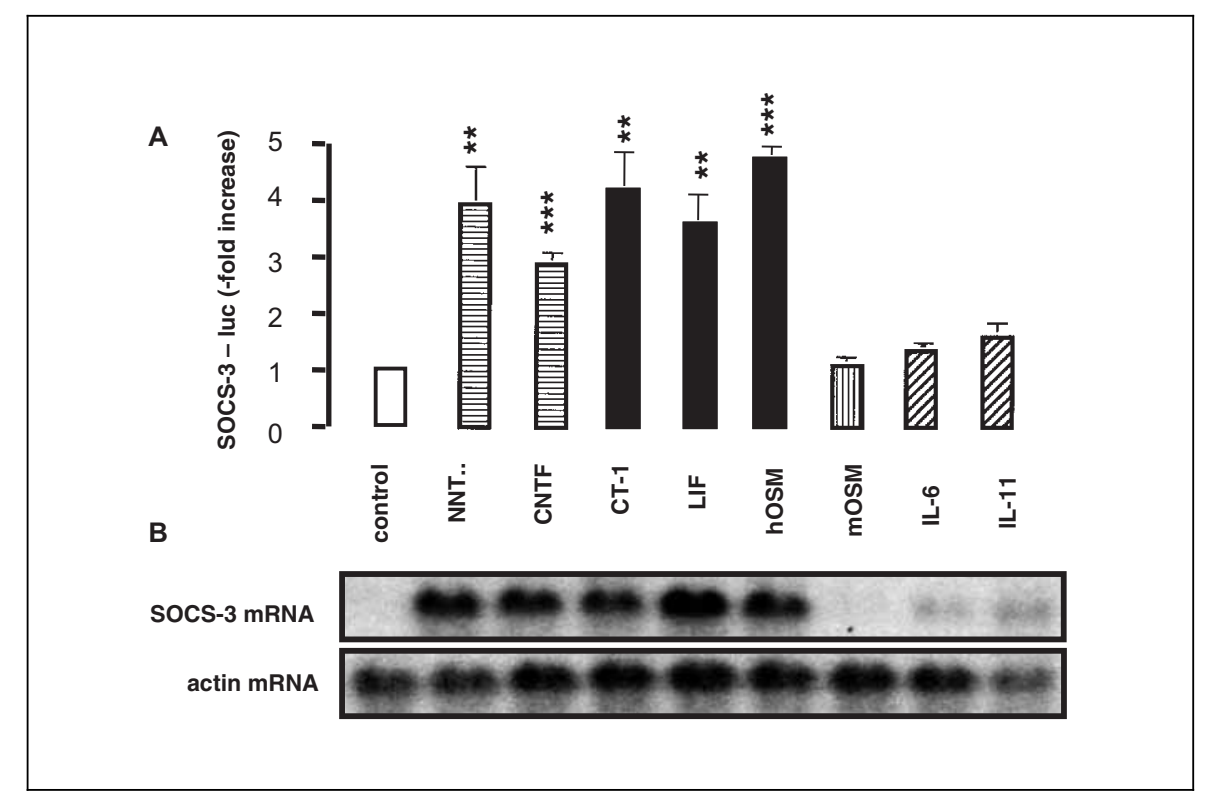

baseline by NNT-1/BSF-3, CNTF, CT-1, LIF and hOSM. In contrast, no significant increase in promoter activity could be detected in this series of experiments by mOSM, IL-6 and IL-1 1, respectively. Results are the mean values of four independently performed experiments with $n=3$ per experiment (fig. 4A). Using Northern blot analysis, SOCS-3 mRNA expression was potently induced at 45 min by NNT-1/BSF-3, CNTF, CT-1, LIF and hOSM. A weak stimulation was also induced by IL-6 and IL-11, while mOSM exhibited no effect. A representative experiment out of three is shown (fig. 4B).

\section{POMC Promoter Activity and ACTH Secretion by Various gp130 Cytokines}

Promoter activity of a $-706 /+64$ rat POMC promoter-luciferase construct (fig. 5A) and ACTH secretion (fig. 5B) was examined following incubation of AtT-20 cells with different gp130 cytokines in an equimolar concentration of $10.0 \mathrm{n} M$. POMC promoter activity was significantly stimulated 2- to 4-fold above baseline by NNT-1/BSF-3, CNTF, CT-1, LIF and hOSM. In contrast, no significant increase in promoter activity was detected in this series of experiments by mOSM, IL-6 and IL-11, respectively. Results are the mean values of four independently performed experiments with $\mathrm{n}=3$ per experiment. Following incubation of AtT-20 cells for $24 \mathrm{~h}$ with equimolar concentrations $(10.0 \mathrm{n} M)$ of each cytokine tested, ACTH secretion was stimulated approximately 2.0 -fold by NNT-1/BSF-3 and CNTF, approximately 2.5 - to 3.0- fold by CT-1, LIF and hOSM, and approximately 1.5 -fold by IL-6 and IL-11, respectively. mOSM did not cause a significant stimulation of ACTH secretion above baseline (fig. 5B).

\section{Discussion}

Our study demonstrates that LIF, hOSM and CT-1 (LIFR/gp130 ligands), as well as CNTF and NNT-1/ BSF-3 (CNTFR $\alpha /$ LIFR/gp130 ligands) are potent stimuli of murine corticotroph AtT-20 cell function. IL-11 (IL$11 \mathrm{R} / \mathrm{gp} 130$ ligand) and IL-6 (IL-6R/gp130 ligand) are relatively weak direct stimuli of corticotroph function, whereas mOSM (OSMR/gp130 ligand) exhibits no bioactivity on corticotroph AtT-20 function.

\section{CNTFR Complex Ligands Are Potent Stimuli of Corticotroph Function, Comparable to LIFR Complex Ligands}

The CNTFR $\alpha /$ LIFR/gp130 complex binds specifically CNTF as well as the recently cloned cytokine NNT-1/ BSF-3 [18, 19-22]. Recently, we have demonstrated NNT-1/BSF-3 to be a potent stimulator of corticotroph function in vitro inducing Jak-STAT-dependent gene expression, negatively regulated by SOCS-3 [12]. CNTF was also found to be a stimulator of corticotroph function [12]. The current data, using equimolar concentrations of each cytokine tested, confirm our previous finding that 


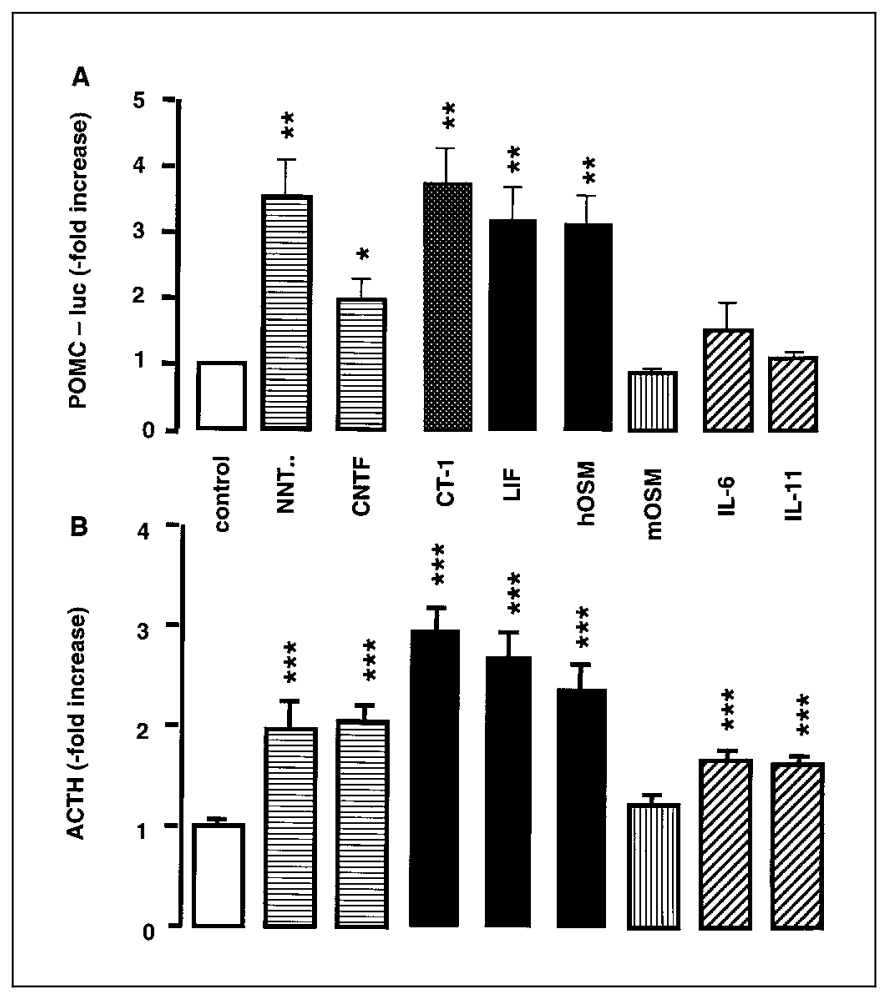

Fig. 5. Effects of gp130 cytokines on corticotroph POMC promoter activity and ACTH secretion. Significant differences are indicated: $* \mathrm{p}<0.05 ; * * \mathrm{p}<0.01 ; * * * \mathrm{p}<0.001$ vs. control. A Corticotroph AtT-20 cells were incubated with equimolar concentrations (10 $\mathrm{n} M)$ of various gp 130 cytokines for $6 \mathrm{~h}$. Reporter gene activity of a transiently transfected $-706 /+64$ rat POMC promoter-luciferase (luc) construct was assayed. Reporter gene activity induced by the various gp130 cytokines was calculated as $\mathrm{x}$-fold increase in comparison to an unstimulated control. B AtT-20 cells were incubated with equimolar concentrations $(10 \mathrm{nM})$ of various gp130 cytokines for $24 \mathrm{~h}$ and ACTH was assayed in the supernatants. ACTH secretion induced by the various gp 130 cytokines was calculated as $\mathrm{x}$-fold increase in comparison to an unstimulated control.

NNT-/BSF-3 and CNTF are potent modulators of corticotroph function. NNT-1/BSF-3 is a similarly potent modulator of corticotroph function as are LIF, hOSM and CT-1 (LIFR/gp130 ligands). In comparison to NNT-1/ BSF-3, CNTF seems to be less potent in the stimulation of corticotroph function in vitro.

\section{IL-6 and IL-11 Are Relatively Weak Direct Stimuli of Corticotroph Function \\ IL-6R is expressed in fetal [10] and postmortem hu-} man pituitaries [23] and pituitary corticotroph adenomas [23]. IL-6 has been demonstrated to stimulate POMC gene expression and ACTH secretion in human cortico- troph adenoma cell cultures [24]. Also, the IL-6R is expressed in murine corticotrophs [25] and corticotroph AtT-20 cells (data not shown). In AtT-20 cells, IL-6 has been reported to stimulate POMC gene expression [15] and ACTH secretion [13, 14, 16]. Also, in our current study, IL-6 modestly but significantly stimulates ACTH secretion, but demonstrates no significant effect on the POMC promoter construct. IL-6 also fails to significantly stimulate STAT-dependent SOCS-3 promoter activity and has only a slight effect on SOCS-3 gene expression. In comparison to equimolar concentrations of other gp130 cytokines, IL-6 shows only a minor effect as direct stimulator of corticotroph AtT-20 cell function in vitro. These data are similar to our previous observation of IL-6 exhibiting no significant stimulation of STAT-dependent SOCS-3 promoter activation in AtT-20 cells [26]. However, these in vitro findings do not diminish the putative major role of IL-6 as an inflammatory cytokine stimulating HPA axis activation. Firstly, IL-6 has been shown to induce the secretion of arginine vasopressin from the hypothalamus [27] and corticotrophin-releasing hormone from immortalized cell lines [28], thus IL-6 probably indirectly stimulates corticotroph function via hypothalamic activation. However, IL-6 injection in mice deficient in corticotrophin-releasing hormone also results in a profound increase in ACTH levels, even higher than in wildtype animals [25]. This might be explained by indirect effects of IL-6 via other paracrine/endocrine mediators as well as some direct stimulatory effects of IL- 6 on pituitary corticotrophs. Paracrine effects of IL- 6 might also be responsible for the finding of IL-6 being almost equally potent to LIF and hOSM in inducing ACTH secretion from primary human fetal pituitary cultures [10]. Secondly, IL-6 is a potent direct stimulator of adrenocortical function in vitro [29, 30].

Expression of the IL-11R has been demonstrated in postmortem human pituitaries [17, 23] and pituitary corticotroph adenomas [23], as well as murine pituitaries [17] and corticotroph AtT-20 cells [17]. We have previously shown IL-11 to stimulate STAT-dependent SOCS-3 and POMC gene expression and ACTH secretion in AtT-20 cells [17]. The current data, using equimolar amounts of each cytokine tested, exhibit IL-11 to be a relatively weak inducer of corticotroph function in comparison to other gp 130 cytokines. While in our previous studies a modest but significant effect of IL-11 on SOCS-3 and POMC promoter activity could be demonstrated [17, 31], in the current study no significant induction of SOCS-3 and POMC promoter activity was observed. These discrepant findings might be explained by varying condi- 
tions for cell culture and luciferase assay. This observation again underlines the necessity for comparative studies in order to directly compare the potency of different cytokines.

hOSM and mOSM Have Different Effects on Murine Corticotrophs, Suggesting that LIFR/gp130 (OSMR

Type I), but Not OSMR/gp130 (OSMR Type II) Is

Important in Corticotroph Signaling

We show differential effects of human and murine OSM on corticotroph function. While cloning of hOSM has been reported in 1989 [32], the cloning of mOSM was first published in 1996 [33]. Earlier studies using hOSM demonstrated stimulation of basal and corticotrophinreleasing hormone-induced POMC transcription and ACTH secretion in murine corticotroph AtT-20 cells [79] as well as ACTH secretion in rat primary pituitary cultures [11, and Kim person. commun.] and in human fetal primary pituitary cultures [10]. In human cells, hOSM can bind to the LIFR/gp130 (OSMR type I) as well as to the OSMR/gp130 (OSMR type II) complex [34-36]. Due to strict species specificity of OSM binding to the OSMR/ gp130 complex [36], in murine cells hOSM binds exclusively to the LIFR/gp130 complex [34]. Thus, the earlier studies [7-9, 11] did not examine the putative role of the OSMR/gp130 complex in corticotroph function, but rather the LIFR/gp130 physiology [34]. We therefore compared in murine corticotroph AtT-20 cells the effects of hOSM, acting as a ligand to the LIFR/gp130 complex in murine cell systems $[34,36]$, with the effects of mOSM, binding exclusively to the OSMR/gp 130 complex but failing to bind to the LIFR/gp130 complex [34-36]. Incubation of AtT-20 cells with hOSM resulted in a potent stimulation of STAT3 and STAT1 comparable to the stimulation induced by LIF. In addition, STAT-dependent POMC promoter activity and ACTH secretion was also potently stimulated by hOSM, as had been described before [7-9]. In contrast, incubation of AtT-20 cells with mOSM failed to induce any STAT-dependent downstream events (fig. 1-5), while bioactivity of the mOSM used was demonstrated in murine adrenocortical Y-1 cells [37]. RT-PCR expression studies of the different receptor subunits involved in LIFR/gp130 and OSMR/gp130 complex formation exhibited murine pituitary tissue and corticotroph AtT-20 cells to express gp130 and LIFR subunits [12]. In contrast, expression of the OSMR subunit was only detected in pituitary tissue, while AtT-20 cells did not express the OSMR subunit (data not shown). Our data demonstrate hOSM and mOSM to display differential effects on murine corticotroph function. While
hOSM (associated with OSMR type I) is a potent stimulus of corticotroph function, mOSM (association with OSMR type II) has no significant effects.

\section{CT-1 Is a New Modulator of Corticotroph Function}

CT-1 has originally been named for its ability to stimulate hypertrophy of cardiac myocytes [38]. CT-1 is expressed in the heart and various other tissues [38]. CT-1 signaling involves the LIFR/gp130 complex [39]. In addition, for CT-1 signaling a third specific receptor component has been suggested [39], which would result in a CT1R/LIFR/gp130 complex similar to the tripartite CNTFR $\alpha / L I F R / g p 130$ complex. In vivo, systemic administration of CT-1 alone and combined with IL-1 resulted in an increase in corticosterone levels [40], which might be due to HPA axis activation at various levels, e.g. pituitary or adrenal. In AtT-20 cells, CT-1 potently stimulates corticotroph STAT phosphorylation, STAT-dependent SOCS-3 promoter activity and gene expression as well as ACTH secretion. The magnitude of corticotroph activation by CT- 1 is comparable to the effects observed by LIF, hOSM, NNT-1/BSF-3 or CNTF. Thus, we could demonstrate CT-1 to be a potent modulator of corticotroph cell function in vitro. No expression of CT-1 could be demonstrated by RT-PCR in postmortem human pituitaries and various pituitary tumors including corticotroph adenomas [23], suggesting no role of CT-1 as an auto-/paracrine factor in pituitary function. However, CT-1 can be measured in the circulation, and CT-1 levels in blood were found to correlate with the degree of heart failure in man [41, 42]. So, stimulatory effects of CT-1 on pituitary corticotroph function might be of endocrine instead of auto-/paracrine mode. Patients with chronic heart failure and cachexia have been shown to exhibit increased serum levels of cortisol [43], which - according to our data - might be partially mediated by endocrine stimulation of the HPA axis by CT-1. This hypothesis merits further evaluation.

In summary, this comparative in vitro study of the action of gp130 cytokines on murine corticotroph AtT-20 cells shows LIF, hOSM, CT-1, CNTF and NNT-1/BSF-3 to be major stimuli of the corticotroph Jak-STAT signaling cascade. In contrast, IL- 6 and IL-1 1 show only modest effects on corticotroph function, whereas no significant effect of mOSM on corticotroph function could be detected. In conclusion, LIFR ligands (LIF, hOSM, CT-1) and CNTFR ligands (CNTF, NNT-1/BSF-3) are similarly potent direct stimuli of corticotroph function in vitro. CT-1 is a hitherto unknown modulator of corticotroph function in vitro, which might act by endocrine rather 
than para-/autocrine mechanisms. Differential effects of hOSM and mOSM on corticotroph function demonstrate the LIFR/gp130 complex (OSMR type I) but not OSMR/ gp130 (OSMR type II) to be of physiologic relevance in neuroimmunoendocrine modulation of corticotroph function. Thus, despite redundant effects of several gp 130 cytokines on corticotroph function, this study could demonstrate specific differences in the potency of different gp130 cytokines to activate corticotroph Jak-STAT signaling and function. This specific pattern of gp130 cytokine action on corticotrophs further contributes to our understanding of the neuroimmunomodulation of corticotroph function. Further comparative studies should also examine differences in gp130 cytokines with respect to their ability to directly induce corticotroph versus adrenocortical function. The - at first glance -redundant neuroimmunoendocrine cytokine network might turn out to have distinct specific 'major players' at corticotroph as well as at adrenocortical level.

\section{Acknowledgment}

This study was supported by grants from the 'Deutsche Forschungsgemeinschaft' (AU 139/2-1) and the 'Friedrich-Baur Stiftung' (0055/2001). This work contains parts of the unpublished doctoral thesis of F.B.K. at the Ludwig Maximilians University of Munich, Germany. We gratefully acknowledge skillful technical assistance by $\mathrm{S}$. Hengge.

\section{References}

1 Heinrich PC, Behrmann I, Müller-Newen G, Schaper F, Graeve L: Interleukin-6-type cytokine signaling through the gp130/Jak/STAT pathway. Biochem J 1998;334:297-314.

2 Auernhammer CJ, Melmed S: Leukemia-inhibitory factor-neuroimmune modulator of endocrine function (review). Endocr Rev 2000; 21:313-345.

3 Arzt E: gp130 cytokine signaling in the pituitary gland: A paradigm for cytokine-neuroendocrine pathways (review). J Clin Invest 2001;108:1729-1733.

4 Melmed S: Series introduction: The immunoneuroendocrine interface (review). J Clin Invest 2001;108:1563-1566.

5 Chesnokova V, Melmed S: Minireview: Neuroimmuno-endocrine modulation of the hypothalamic-pituitary-adrenal (HPA) axis by gp130 signaling molecules. Endocrinology 2002;143:1571-1574.

6 Auernhammer CJ, Melmed S: The central role of SOCS-3 in integrating the neuro-immunoendocrine interface (review). J Clin Invest 2001; 108:1735-1740.

7 Akita S, Webster J, Ren SG, Takino H, Said J, Zand O, Melmed S: Human and murine pituitary expression of leukemia inhibitory factor. Novel intrapituitary regulation of adrenocorticotropin hormone synthesis and secretion. $\mathrm{J}$ Clin Invest 1995;95:1288-1298.

8 Ray DW, Ren SG, Melmed S: Leukemia inhibitory factor (LIF) stimulates proopiomelanocortin (POMC) expression in a corticotroph cell line. Role of STAT pathway. J Clin Invest 1996;97:1852-1859.

9 Stefana B, Ray DW, Melmed S: Leukemia inhibitory factor induces differentiation of pituitary corticotroph function: An immuno-neuroendocrine phenotypic switch. Proc Natl Acad Sci USA 1996;93:12502-12506.
10 Shimon I, Yan X, Ray DW, Melmed S: Cytokine-dependent gp130 receptor subunit regulates human fetal pituitary adrenocorticotropin hormone and growth hormone secretion. J Clin Invest 1997;100:357-363.

11 Kim DS, Choi HS, Park YS, Kim TW: Effects of oncostatin $\mathrm{M}$ on hormone release of rat pituitary cells in primary culture. J Korean Med Sci 2000;15:323-326.

12 Auernhammer CJ, Isele NB, Kopp FB, Spoettl G, Cengic N, Weber MM, Senaldi G, Engelhardt D: Novel neurotrophin-1/B-cell stimulating factor-3 (cardiotrophin-like cytokine) stimulates corticotroph function via a signal transducer and activator of transcription-dependent mechanism negatively regulated by suppressor of cytokine signaling-3. Endocrinology 2003; 144:1202-1210.

13 Woloski BM, Smith EM, Meyer WJ 3rd, Fuller GM, Blalock JE: Corticotropin-releasing activity of monokines. Science 1985;230:10351037.

14 Fukata J, Usui T, Naitoh Y, Nakai Y, Imura H: Effects of recombinant human interleukin-1 $\alpha$, $-1 \beta, 2$ and 6 on ACTH synthesis and release in the mouse pituitary tumour cell line AtT-20. J Endocrinol 1989;122:33-39.

15 Katahira M, Iwasaki Y, Aoki Y, Oiso Y, Saito $\mathrm{H}$ : Cytokine regulation of the rat proopiomelanocortin gene expression in AtT-20 cells. Endocrinology 1998;139:2414-2422.

16 Li QL, Jansen E, Friedman TC: Regulation of prohormone convertase 1 (PC1) by gp130related cytokines. Mol Cell Endocrinol 1999; 158:143-152.

17 Auernhammer CJ, Melmed S: Interleukin-11 stimulates proopiomelanocortin gene expression and adrenocorticotropin secretion in corticotroph cells: Evidence for a redundant cytokine network in the hypothalamo-pituitary-adrenal axis. Endocrinology 1999;140:15591566.
18 Senaldi G, Varnum BC, Sarmiento U, Starnes C, Lile J, Scully S, Guo J, Elliott G, McNinch J, Shaklee CL, Freeman D, Manu F, Simonet WS, Boone T, Chang MS: Novel neurotrophin1/B cell-stimulating factor-3: A cytokine of the IL-6 family. Proc Natl Acad Sci USA 1999;96: 11458-11463.

19 Shi Y, Wang W, Yourey PA, Gohari S, Zukauskas D, Zhang J, Ruben S, Alderson RF: Computational EST database analysis identifies a novel member of the neuropoietic cytokine family. Biochem Biophys Res Commun 1999; 262:132-138.

20 Elson GC, Lelievre E, Guillet C, Chevalier S, Plun-Favreau H, Froger J, Suard I, de Coignac $\mathrm{AB}$, Delneste Y, Bonnefoy JY, Gauchat JF, Gascan H: CLF associates with CLC to form a functional heteromeric ligand for the CNTF receptor complex. Nat Neurosci 2000;3:867872.

21 Plun-Favreau H, Elson G, Chabbert M, Froger J, deLapeyriere O, Lelievre E, Guillet C, Hermann J, Gauchat JF, Gascan H, Chevalier S: The ciliary neurotrophic factor receptor alpha component induces the secretion of and is required for functional responses to cardiotrophin-like cytokine. EMBO J 2001;20:16921703.

22 Lelievre E, Plun-Favreau H, Chevalier S, Froger J, Guillet C, Elson GC, Gauchat JF, Gascan $\mathrm{H}$ : Signaling pathways recruited by the cardiotrophin-like cytokine/cytokine-like factor-1 composite cytokine: Specific requirement of the membrane-bound form of ciliary neurotrophic factor receptor $\alpha$ component. J Biol Chem 2001;276:22476-22484.

23 Hanisch A, Dieterich KD, Dietzmann K, Ludecke K, Buchfelder M, Fahlbusch R, Lehnert $\mathrm{H}$ : Expression of members of the interleukin-6 family of cytokines and their receptors in human pituitary and pituitary adenomas. J Clin Endocrinol Metab 2000;85:4411-4414. 
24 Pereda MP, Lohrer P, Kovalovsky D, Perez Castro C, Goldberg V, Losa M, Chervin A, Berner S, Molina H, Stalla GK, Renner U, Arzt $\mathrm{E}$ : Interleukin-6 is inhibited by glucocorticoids and stimulates ACTH secretion and POMC expression in human corticotroph pituitary adenomas. Exp Clin Endocrinol Diabetes 2000; 108:202-207.

25 Bethin KE, Vogt SK, Muglia LJ: Interleukin-6 is an essential, corticotropin-releasing hormone-independent stimulator of the adrenal axis during immune system activation. Proc Natl Acad Sci USA 2000;97:9317-9322.

26 Auernhammer CJ, Bousquet C, Melmed S: Autoregulation of pituitary corticotroph SOCS-3 expression: Characterization of the murine SOCS-3 promoter. Proc Natl Acad Sci USA 1999;96:6964-6969.

27 Chikanza IC, Petrou P, Chrousos G: Perturbations of arginine vasopressin secretion during inflammatory stress. Pathophysiologic implications (review). Ann NY Acad Sci 2000;917: 825-834.

28 Mulchahey JJ, Regmi A, Sheriff S, Balasubramaniam A, Kasckow JW: Coordinate and divergent regulation of corticotropin-releasing factor (CRF) and CRF-binding protein expression in an immortalized amygdalar neuronal cell line. Endocrinology 1999;140:251-259.

29 Path G, Scherbaum WA, Bornstein SR: The role of interleukin-6 in the human adrenal gland (review). Eur J Clin Invest 2000;30(suppl 3):91-95.

30 Franchimont D, Bouma G, Galon J, Wolkersdorfer GW, Haidan A, Chrousos GP, Bornstein SR: Adrenal cortical activation in murine colitis. Gastroenterology 2000;119:1560-1568.
31 Auernhammer CJ, Chesnokova V, Bousquet C, Melmed S: Pituitary corticotroph SOCS-3: Novel intracellular regulation of leukemia-inhibitory factor-mediated proopiomelanocortin gene expression and adrenocorticotropin secretion. Mol Endocrinol 1998;12:954-961.

32 Malik N, Kallestad JC, Gunderson NL, Austin SD, Neubauer MG, Ochs V, Marquardt H, Zarling JM, Shoyab M, Wei CM: Molecular cloning, sequence analysis, and functional expression of a novel growth regulator, oncostatin M. Mol Cell Biol 1989;9:2847-2853.

33 Yoshimura A, Ichihara M, Kinjyo I, Moriyama M, Copeland NG, Gilbert DJ, Jenkins NA, Hara T, Miyajima A: Mouse oncostatin M: An immediate early gene induced by multiple cytokines through the JAK-STAT5 pathway. EMBO J 1996; 15:1055-1063

34 Lindberg RA, Juan TS, Welcher AA, Sun Y, Cupples R, Guthrie B, Fletcher FA: Cloning and characterization of a specific receptor for mouse oncostatin M. Mol Cell Biol 1998;18: 3357-3367.

35 Tanaka M, Hara T, Copeland NG, Gilbert DJ, Jenkins NA, Miyajima A: Reconstitution of the functional mouse oncostatin M (OSM) receptor: Molecular cloning of the mouse OSM receptor beta subunit. Blood 1999;93:804-815.

36 Wang Y, Robledo O, Kinzie E, Blanchard F, Richards C, Miyajima A, Baumann H: Receptor subunit-specific action of oncostatin $\mathrm{M}$ in hepatic cells and its modulation by leukemia inhibitory factor. J Biol Chem 2000;275: 25273-25285.

37 Auernhammer CJ, Dorn F, Dietrich A, Engelhardt D, Weber MM: Murine oncostatin M stimulates corticosterone secretion in murine adrenocortical Y-1 cells (abstract). Exp Clin Endocrinol Diabetes 2001;109(suppl 1):S19.
38 Latchman DS: Cardiotrophin-1: A novel cytokine and its effects in the heart and other tissues (review). Pharmacol Ther 2000;85:29-37.

39 Robledo O, Fourcin M, Chevalier S, Guillet C, Auguste P, Pouplard-Barthelaix A, Pennica D, Gascan H: Signaling of the cardiotrophin-1 receptor. Evidence for a third receptor component. J Biol Chem 1997;21;272:4855-4863.

40 Benigni F, Fantuzzi G, Sacco S, Sironi M, Pozzi P, Dinarello CA, Sipe JD, Poli V, Cappelletti M, Paonessa G, Pennica D, Panayotatos N, Ghezzi P: Six different cytokines that share GP130 as a receptor subunit, induce serum amyloid $\mathrm{A}$ and potentiate the induction of interleukin- 6 and the activation of the hypothalamus-pituitary-adrenal axis by interleukin1. Blood 1996;87:1851-1854.

41 Talwar S, Squire IB, Downie PF, O'Brien RJ, Davies JE, Ng LL: Elevated circulating cardiotrophin-1 in heart failure: Relationship with parameters of left ventricular systolic dysfunction. Clin Sci (Lond) 2000;99:83-88.

$42 \mathrm{Ng}$ LL, O’Brien RJ, Demme B, Jennings S: Non-competitive immunochemiluminometric assay for cardiotrophin-1 detects elevated plasma levels in human heart failure. Clin Sci (Lond) 2002;102:411-416.

43 Anker SD, Ponikowski PP, Clark AL, Leyva F, Rauchhaus M, Kemp M, Teixeira MM, Hellewell PG, Hooper J, Poole-Wilson PA, Coats AJ: Cytokines and neurohormones relating to body composition alterations in the wasting syndrome of chronic heart failure. Eur Heart J 1999;20:683-693. 